\title{
Consequences of Learned Helplessness and Recognition of the State of Cognitive Exhaustion in Persons with Mild Intellectual Disability
}

\author{
Michał Gacek ', Tomasz Smoleń', Władysława Pilecka² \\ ${ }^{1}$ Chair of Psychology, The Pedagogical University of Kraków, ul. Podchorążych 2, 30-084, Kraków, Poland \\ ${ }^{2}$ Institute of Psychology, Jagiellonian University, ul. Ingardena 6, 30-060, Kraków, Poland
}

ABSTRACT

Persons with intellectual disability are a group at risk of being exposed to overly demanding problem-solving situations, which may produce learned helplessness. The research was based on the informational model of learned helplessness. The consequences of exposure to an unsolvable task and the ability to recognize the symptoms of cognitive exhaustion were tested in 120 students with mild intellectual disability. After the exposure to the unsolvable task, persons in the experimental group obtained lower results than the control group in the escape/avoidance learning task, but a similar result was found in the divergent thinking fluency task. Also, participants in the experimental group had difficulties recognizing the symptoms of the cognitive exhaustion state. After a week's time, the difference in escape/avoidance learning performance was still observed. The results indicate that exposure to unsolvable tasks may negatively influence the cognitive performance in persons with intellectual disability, although those persons may not identify the cognitive state related to lowered performance.

\section{KEYWORDS}

learned helplessness, cognitive exhaustion avoidance learning, divergent thinking, fluency, intellectual disability

\section{INTRODUCTION}

Intellectual disability is defined by deficits in intellectual and everyday adaptive functioning, with an onset in the developmental period (American Psychiatric Association [APA], 2013; Schalock et al., 2007). Most persons who fulfill the diagnostic criteria for this category fall within the range of mild severity. Although it is estimated that there exist over 250 biomedical causes of intellectual disability (Greenspan, 1999) and over 750 genetic syndromes related to this category (Harris, 2006; Hodapp, 2001), genetic and organic etiology is not identified in 30-50\% of cases (Goharpey, Crewther, \& Crewther, 2009; Hodapp, Burack, \& Zigler, 1998; Iarocci \& Petrill, 2012). Mild intellectual disability individuals with no specific genetic etiology usually possess a normal appearance, without physical stigmata indicating their state. In accordance with the current educational policies, such individuals are often placed in inclusive educational units (Snyder \& Dillow, 2015;
United Nations Educational, Scientific, and Cultural Organization [UNESCO], 2009). The common absence of visible signs of disability and the context of being placed among students from the general population increase the risk of being exposed to overly demanding cognitive tasks within everyday situations. Such an exposure may lead to learned helplessness, having a negative impact on a person's performance.

Learned helplessness was first described based on the results obtained in animal studies. In the original experiments, dogs exposed to inescapable electric shocks demonstrated performance deficits in subsequent learning tasks (Overmier \& Seligman, 1967; Seligman \& Maier, 1967). The significance of these studies lay not in the mere description Corresponding author: Michal Gacek, PhD, The Pedagogical University of Kraków, 30-084, ul. Podchorążych 2, Kraków, Poland. Phone: +48 501827140. E-mail:m.j.gacek@wp.pl 
of the deficits observed when aversive stimuli were applied but rather in the theoretical mechanism proposed by the authors (Overmier, 2002). According to the learned helplessness hypothesis, perceived uncontrollability leads to expectations about the future which impair the learning process (LoLordo \& Taylor, 2001; Maier \& Seligman, 1976). The performance deficits observed in learning tasks were described as motivational and cognitive in nature. The first of these deficits is reflected in the fact that the subject initiated fewer responses, and the second deficit is reflected in the fact that even when the correct response was given, the subject was less likely to learn its relevance. Despite the fact that during the first two decades from the date of the theory's introduction numerous studies involving animal and human subjects have demonstrated the negative effects of learned helplessness (for a review see Peterson, Maier, \& Seligman, 1993), researchers continue to study this concept, attempting to refine the original theory by identifying other factors that influence behavior, for example, investigating the role of failure feedback (Hatfield \& Job, 1998; Matute, 1994), or the attentional deficits associated with the condition (Minor, Jackson, \& Maier, 1984; Reed \& Antonova, 2007), or the possibility that alternative principles explain the described phenomenon.

From the field of cognitive psychology, an informational approach to learned helplessness, proposed by Sędek and Kofta (1990), has emerged. These authors pointed out that the objective uncontrollability, crucial to the development of helplessness, may have different effects on behavior as a result of various factors (e.g., Bukowski, Asanowicz, Marzecova, \& Lupianez, 2014; Mikulincer, Kedem, \& Zilkha-Segal, 1989; Pittman \& D’Agostino, 1989; Pittman \& Pittman, 1980). According to Sędek and Kofta (1990) learned helplessness occurs when a person initially does not recognize that the task is beyond their control because such recognition would mean that the person would not be involved cognitively in the task. When a person tries to exert control by finding a solution but repeatedly fails to do so, they experience a state of cognitive exhaustion. Such a state is characterized by diminished and less efficient usage of a person's cognitive resources. The prolonged lack of success inhibits the tendency to engage in the production of new thoughts and ideas, which leads to difficulties in the tackling of subsequent tasks, especially those that are novel and complex. Persons in a state of cognitive exhaustion find demanding mental activity unpleasant and experience negative emotions (Sędek \& Kofta, 1990; Von Hecker, Sędek, \& McIntosh, 2000). Their cognitive impairments closely resemble those present in persons with symptoms of depression (Von Hecker \& Sędek, 1999; Von Hecker, Sędek, \& Brzezicka, 2013). In this view, in contrast to the original theory, learned helplessness is not something that follows the behavioral acts, but a phenomenon related to the difficulties in the hypothesis-testing stage of action development, when a person tries to construct a successful action program in order to achieve cognitive gain (Kofta \& Sędek, 1999; Sędek \& Kofta, 1990; Sędek, Kofta, \& Tyszka, 1993; Von Hecker et al., 2000).

Learned helplessness symptoms are often linked to the psychological characteristics of persons with intellectual disability (Heward, 2006; Richards, Brady, \& Taylor, 2015). The results of studies indicate that persons with intellectual disability present more evidence of helplessness than children matched on mental age (Gargiulo \& O'Sullivan, 1986; Gargiulo, O’Sullivan, \& Barr, 1987). Such results were obtained at mental age levels of above seven years, which lead one to the conclusion that helplessness symptoms are acquired gradually over the years (Weisz, 1979, 1981, 1999). In other studies, learned helplessness symptoms in persons with intellectual disability were associated with attentional functioning (Utley, Hoehn, Soraci, \& Baumeister, 1993), communicative interactions (Basil, 1992), and depression (Reynolds \& Miller, 1985). So far, none of the conducted studies have referred to the informational model of learned helplessness.

The purpose of the present study was to test the effects that exposure to an unsolvable task has on performance in subsequent cognitive tasks in persons with intellectual disability and to evaluate whether persons in this group are able to recognize the symptoms of a state of cognitive exhaustion. We used four measures. Firstly, the discrimination task based on the description given by Sędek and Kofta (1990) was used to invoke the cognitive exhaustion state. Two tasks were used in the test phase: the escape/avoidance learning task (Sędek \& Kofta, 1990), measuring the performance in a situation which requires hypothesistesting, and the divergent thinking fluency task, based on a concept frequently used in studies on creativity (Benderek, Muhlmann, Jauk, \& Neubauer, 2013), measuring performance in a situation in which a person puts effort into the production of as many ideas as possible. It was assumed that the exposure to an unsolvable task would negatively influence performance in both subsequent tasks. In order to test the perception of the cognitive exhaustion symptoms, we used the questionnaire developed by Sędek and Kofta. Since persons who perform poorly at tasks tend to overestimate their performance due to a lack of ability to recognize their deficits (Dunning, Johnson, Ehrlinger, \& Kruger, 2003; Ehrlinger \& Dunning, 2003; Ehrlinger, Johnson, Banner, Dunning, \& Kruger, 2008) and persons with intellectual disability may be even more prone than persons in the general population to experience difficulties in connecting their performance to internal causes and effectively judging their ability (Wehmeyer, 1994, 2001), it was predicted that persons with intellectual disability would not identify the cognitive exhaustion state symptoms. We also predicted that, after a week, the difference in performance would still be present due to the fact that the learning ability during the first meeting was diminished. The discrimination task, the escape/avoidance learning task, and the cognitive exhaustion symptoms questionnaire were modified to fit the purpose of the study in the group of persons with intellectual disability.

Four hypotheses were offered in reference to persons with mild intellectual disability:

1. The exposure to an unsolvable task decreases learning effectiveness.

2. The exposure to an unsolvable task decreases divergent thinking fluency.

3. Symptoms of the cognitive exhaustion state are not identified properly.

4. The exposure to an unsolvable task has a long-term effect on learning effectiveness. 


\section{MATERIAL AND METHODS}

\section{Participants}

The sample consisted of 120 students ( 62 boys and 58 girls) recruited from a special vocational school for persons with mild intellectual disability in Kraków. The participants' age ranged from 16 to 23 years $\left(M_{\text {age }}=18.07, S D=1.57\right)$. All students had been diagnosed with mild intellectual disability at a psychological-pedagogical counseling centre. We randomly selected students without identified organic etiology, such as Down Syndrome or Fragile-X Syndrome, and no secondary diagnoses, such as sensory impairment or psychopathology. The study was approved by the ethics committee of Jagiellonian University and by the school board. Written consent was obtained from the students and their parents. All participants were informed that their responses would be anonymous and that they could withdraw from the study at any time. From among those who fulfilled the selection criteria, only two students refused to participate in the study. Sixty participants were assigned to the experimental group (30 boys and 30 girls, $M_{\text {age }}=$ $17.67, S D=1.37)$, which was presented with an unsolvable task, and 60 persons to the control group ( 32 boys and 28 girls, $M_{\text {age }}=18.47$, $S D=1.65)$

\section{Measures}

\section{DISCRIMINATION TASK}

The discrimination task was based on Sędek and Kofta (1990). We used 32 cards divided into 16 pairs. Each card was comprised of five features associated with the features on the other card from the pair. The paired features were: "man-woman," "day-night," "dog-cat," "owlpigeon," and "triangle-circle." Depending on the pair, different features were presented on the left or on the right side. An example pair of cards is presented in Figure 1.
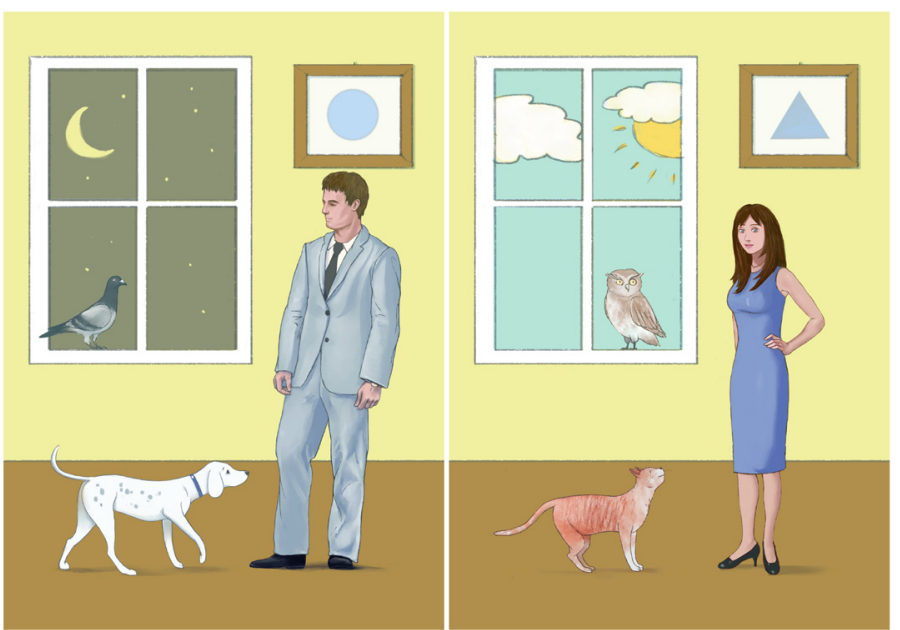

FIGURE 1.

The pair of cards used in the discrimination task.

The discrimination task consisted of six trials. The first three trials were the same in both the experimental and the control group. The experimenter instructed the person to choose a proper card based on one of the features. The person was told that in the first trial, the proper cards are those with the "day" feature. If a person pointed to the card with the day feature, the experimenter said "yes, that's the proper card", if not - "no, that's not the proper card." In the first trial, seven pairs of cards were shown. In the next trial, the experimenter again informed the participant that he or she was required to point to the proper cards, but this time the proper cards needed to be decided upon based on discrimination between two elements: pigeon or owl. Each time a person pointed to the card with the owl, the experimenter said that it was the proper card, while each time the card with the pigeon was chosen, the experimenter said that it was not the proper card. This task consisted of nine pairs of cards. In the third trial, consisting of 16 pairs of cards, participants were told that they need to choose a proper card based on four elements. In Trials 4 to 6 , the conditions changed for both the experimental and control group. The experimental group was told that they needed to choose the proper card based on six, eight, and then 10 elements. In this group, the task was unsolvable. The experimenter gave the answer "no, that's not the proper card" at a ratio of 2:1. When each trial was finished, the person was asked which element was correct and the experimenter commented "no, that wasn't the proper element." We decided to provide information about failure in each trial, since we assumed that persons with intellectual disability, due to their lack of criticism, might still consider their answers to be correct, regardless of the informational inconsistency. The control group in Trials 4 to 6 was given solvable problems, each time receiving the true information about whether the element chosen after the trial was or was not correct.

At the end of each consecutive trial, the person was asked to name the proper feature or element and to answer four questions: (a) "How certain are you that you found the correct answer?", (b) "how well do you think you did on this trial?", (c) "how did you feel while solving the 
task?", and (d) "how well do you think you will do on the next trial?" To every question, each person could give answers which were rated on a scale from 1 to 4 , where 1 represented the uncertainty and negative emotions indicating a state of cognitive exhaustion and 4 the absence of such judgments.

\section{ESCAPE/AVOIDANCE LEARNING TASK}

The escape/avoidance learning task was based on the description in Sędek and Kofta (1990). We prepared a computer with three letters on the keyboard marked with yellow, red, and blue paper. The task was comprised of two trials. In each trial, a sequence was presented on the screen: first a green square, then a red square with a five-second exposure time. Then, the screen went blank and, in the case of an incorrect answer, a three-second noise came from the computer's speakers. The first trial was comprised of 10 sequences, and the second trial - of 40 . In the first trial, there was always one key which could stop the noise, no matter if the key was pushed when the green or red square was presented, and in the second trial, one key was associated with the green square and a different with the red one. Also, in both trials, there was one key associated with the noise, which a person could use when the noise had already been activated. The escape/avoidance learning effectiveness was measured by the successful attempts at both preventing the signal and stopping it.

The person was told that the coloured squares would appear on the screen and that the goal of the task was to use one of the marked buttons to prevent the sound which came from the speakers. Information was given that if the correct button was pushed at the right time, the sound would not appear and that with each square, only the first button to be pushed counted. Participants were also informed that when the sound appeared, they could still try to stop it by using one of the marked buttons. Before the task started, the experimenter asked a person to try and push each of the buttons.

\section{DIVERGENT THINKING FLUENCY TASK}

To measure divergent thinking fluency, three questions were developed which would allow us to obtain many possible answers. The number of answers generated by the participants was tabulated. The persons were instructed to give as many answers as possible regarding the situations described by the experimenter. The answers were written down. If a person gave only one answer, the experimenter was allowed to remind that a person was supposed to give as many answers as possible. Later, the experimenter did not prompt anymore. The situations presented to the participants were as follows: (a) "Imagine you're at a cinema and you see a fire somewhere in the room. Tell me what you could do if you found yourself in such a situation. Try to give me as many possible answers as you can;" (b) "Imagine that you want to prepare a pizza. Think about the ingredients you could use as topping. Try to name as many ingredients as possible, even those you don't like;" (c) "Imagine that you want to buy a gift for your brother/sister (always the opposite sex to the participants'). You go to a mall and you can afford to buy anything you want. Name as many things as you can which you could buy."

\section{EXHAUSTION SYMPTOMS QUESTIONNAIRE}

The questionnaire was developed by Sędek and Kofta (1990) to measure the subjective perception of a state of cognitive exhaustion. The item content was simplified for persons with intellectual disability. All the items were related to the cognitive and motivational difficulties which could indicate a state of cognitive exhaustion. The item content was:

(a) "I'm sure that I did well in the tasks I solved";

(b) "I felt that I don't want to solve another task";

(c) "When I was solving the tasks I felt I didn't know what they were about";

(d) "I found pleasure in solving the tasks";

(e) "It was difficult to figure out what the tasks were about";

(f) "I didn't know if my answers were correct or not";

(g) "I felt bored while solving the tasks";

(h) "It was easy to decide what answers I should give and which but tons to press";

(i) "I found it difficult to focus on the tasks";

(j) "I felt good while solving the tasks";

(k) "I found the tasks interesting";

(l) "I didn't really know what to do during the tasks".

Items $1,4,8,10$, and 11 were reversely scored. Each time a person could point to one of the four answers, this was evaluated on a scale of 1 to 4 , with higher numbers indicating higher cognitive exhaustion.

\section{Procedure}

All participants were tested at school in a specially prepared room. The experiment was carried out by two instructed female psychology students. The experimenters met each participant twice. During both meetings, the tested persons solved the discrimination task first, then the escape/avoidance learning task, and finally the divergent thinking fluency task. After finishing of all tasks, participants were asked to fill in the exhaustion symptoms questionnaire.

We manipulated the answers in the discrimination task of the experimental group. The participants in this group received the "no" answers in Trials 4 to 6 in a ratio of 2:1. The answers were not related to the participants' actual performance. At the end of each consecutive trial, the participants answered four questions about the task and pointed to the feature which they had chosen as correct. The participants in the experimental group were informed in Trials 4 to 6 that the feature they had chosen was not the proper one. Those within the control group were given solvable problems and appropriate feedback.

After the discrimination task, the participants were asked to sit in front of the computer where they solved the escape/avoidance learning task. The experimenter read the instruction before each trial and sat behind the tested person when each trial began. When the task was finished, the person was asked to move away from the computer and the divergent thinking fluency task was presented. The experimenter wrote down the answers given to each of the three questions. In the final part of the study, those tested received a questionnaire in which they marked their answers. All participants were told that they could ask about the items if they felt that they did not understand the content. 


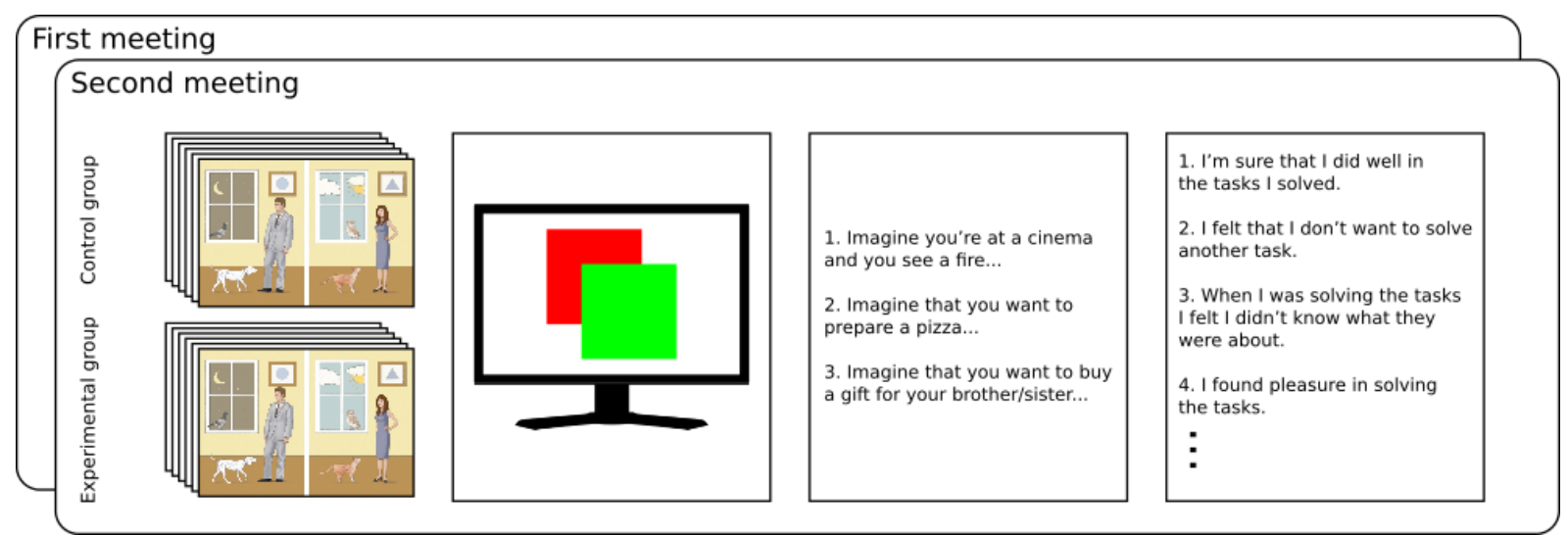

FIGURE 2.

The diagram presenting the experimental procedure.

After a week, a second meeting was held during which the same tasks were given. This time, those who solved the discrimination task in the experimental group received "yes" answers in a 2:1 ratio for Trials 4 to 6 . We wanted to give those in the experimental group the impression that they were easily able to find the correct answer. After each trial, they were told that the feature or element they had chosen was correct. Next, the escape/avoidance learning task and the divergent thinking fluency task were given, and finally, participants filled in the questionnaire for the second time. When the experiment was finished, the purpose of the study was explained to the participants during classes. Figure 2 presents the diagram for the procedure followed.

\section{Operational hypotheses}

We formulated four operational hypotheses which refer to the hypotheses offered in the introduction:

1. In the first meeting, the performance in the escape/avoidance learning task will be worse in the experimental group than in the control group.

2. In the first meeting, the performance in the divergent thinking fluency task will be worse in the experimental group than in the control group.

3. In the first meeting, there will be no difference between the control and experimental group in the exhaustion symptoms questionnaire.

4. In the second meeting, the performance in the escape/avoidance learning task will be worse in the experimental group than in the control group.

\section{RESULTS}

Most of the following analyses were performed with Welch's $t$-test, which is a generalization of the Student $t$-test and intended for use when the samples have unequal variances. The correction for unequal variance may result in non-integer degrees of freedom.

To obtain a single measure of exhaustion, we used the mean value of the answers to questionnaire questions. The measure has a high correlation with an alternative measure-the principal component acquired in a factor analysis with varimax rotation $(r=.97$ for the first meeting and $r=.99$ for the second meeting).

Since one of our hypotheses stated that there was no difference between the groups, it could not be corroborated using frequentist statistical methods because stating the lack of a significant difference is not conclusive on the basis of these methods. To corroborate this hypothesis, we used the Bayes factor $(\mathrm{K})$, that is, the ratio of observed data likelihood given the null hypothesis and the likelihood given an alternative hypothesis. To compute the Bayes factor, we used the BayesFactor package in R (Morey \& Rouder, 2014).

Three participants (male, ages 16, 17, and 19 years, two from the control group) were excluded from further analysis due to their low certainty with regard to performance accuracy in the first three trials of the discrimination task (more than two SDs below the mean). Such a result would suggest that these students at the beginning of the study presented an uncertainty which would not allow for experimental manipulation.

The Pearson's correlation coefficients between the main measures used in the analysis are presented in Table 1. Among the 66 tested correlations, 11 appeared to be statistically significant after applying Benjamini and Yekutieli's (2001) correction for multiple tests.

The answers to the question after each of the trials in the discrimination task were significantly correlated with each other (from $r=.26$ to $r=.72$ ). The mean value of responses to all four questions was used to measure the level of uncertainty and the negative emotions associated with the learned helplessness. The mean values of answers to all the trial questions are presented in Table 2.

The repeated-measures ANOVA test reveals that the certainty changes between Trials 1-3 and 4-6 differently for the control and experimental group, $F(1,115)=98.58, p<.001, \eta^{2}=.16$. A post-hoc test shows that the difference between Trials 1-3 $(M=3.47)$ and 4-6 $(M=$ 3.44) is not significant in the control group, $t(57)=0.73, p=.47, d=$ 0.071 , paired, while the difference ( $M=3.34$ and 2.62 , respectively) is significant in the experimental group, $t(58)=12.47, p<0.001, d=1.79$, paired (see Figure 3). 
TABLE 1.

Correlations Between the Main Measures Used in the Study

\begin{tabular}{ccccccccccccc}
\hline Measures & & 2 & 3 & 4 & 5 & 6 & 7 & 8 & 9 & 10 & 11 & 12 \\
\hline Discrimination tasks 1-3 & 1 & $.45^{* * *}$ & -.19 & -.15 & -.04 & -.06 & -.10 & .06 & -.05 & -.03 & .14 & .05 \\
Discrimination tasks 4-6 & 2 & - & -.17 & -.17 & 0 & -.02 & -.11 & .06 & .02 & .06 & .12 & .01 \\
Learning task, meeting I & 3 & - & - & $.46^{* * *}$ & $.52^{* * *}$ & $.33^{* *}$ & 0 & .21 & .14 & .09 & -.13 & -.17 \\
Learning task, (avoidance), meeting I & 4 & - & - & - & $-.52^{* * *}$ & -.01 & .21 & $-.32^{*}$ & .26 & .2 & -.17 & -.16 \\
Learning task, (escape), meeting I & 5 & - & - & - & - & $.34^{* *}$ & -.20 & $.51^{* * *}$ & -.12 & -.11 & .04 & -.01 \\
Learning task, meeting II & 6 & - & - & - & - & - & .17 & .23 & .08 & .11 & -.17 & -.09 \\
Learning task, (avoidance), meeting II & 7 & - & - & - & - & - & - & $-.54^{* * *}$ & .07 & .1 & -.1 & .05 \\
Learning task, (escape), meeting II & 8 & - & - & - & - & - & - & - & -.09 & -.06 & .04 & .06 \\
Divergent thinking task, meeting I & 9 & - & - & - & - & - & - & - & - & $.75^{* * *}$ & -.28 & -.25 \\
Divergent thinking task, meeting II & 10 & - & - & - & - & - & - & - & - & - & -.17 & -.18 \\
Exhaustion symptoms, meeting I & 11 & - & - & - & - & - & - & - & - & - & - & $.48^{* * *}$ \\
Exhaustion symptoms, meeting II & 12 & - & - & - & - & - & - & - & - & - & - & - \\
\hline
\end{tabular}

Note. ${ }^{*} p<.05,{ }^{* *} p<.01,{ }^{* * *}, p<.001$

\section{TABLE 2}

Answers in the Discrimination Task for Six Trials and Four Questions

\begin{tabular}{ccccc}
\hline Trial & \multicolumn{3}{c}{ Question } & \\
& 1 & 2 & 3 & $3.33(0.77)$ \\
\hline 1 & $3.69(0.59)$ & $3.75(0.47)$ & $3.59(0.59)$ & $3.31(0.69)$ \\
2 & $3.28(0.74)$ & $3.32(0.67)$ & $3.49(0.61)$ & $3.29(0.72)$ \\
3 & $3.19(0.81)$ & $3.22(0.74)$ & $3.41(0.66)$ & $3.12(0.76)$ \\
4 & $2.97(0.9)$ & $2.89(0.91)$ & $3.24(0.71)$ & $3.01(0.8)$ \\
5 & $2.94(0.87)$ & $2.81(0.9)$ & $3.15(0.79)$ & $3.02(0.86)$ \\
\hline
\end{tabular}

Note. Standard deviations (in parentheses)

\section{Hypothesis 1: Escape/avoidance Learning in the First Meeting}

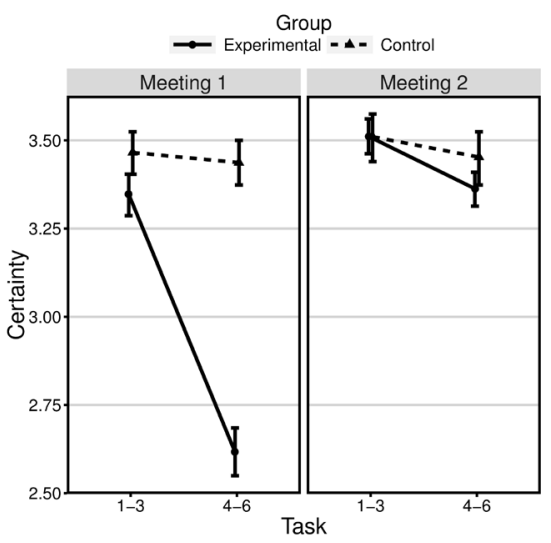

FIGURE 3.

Mean certainty of accuracy for the first and second three tasks in the first and second series (meeting) shown for the control and experimental group. The bars show $95 \%$ confidence intervals for the means.
The escape/avoidance learning task consisted of two series. The first one consisted of ten trials and the second one of forty trials. Two measures were analyzed in the task: the proportion of prevented noise signals and the proportion of stopping not avoided signals during their presentation. The measures were correlated both in the first meeting, $r$ $=.3,95 \% \mathrm{CI}[.17, .41]$, and in the second meeting, $r=.5,95 \% \mathrm{CI}[.38$, .59]. Both floor and ceiling performance levels were observed in the case of preventing noise signals ( $29 \%$ and $9 \%$, accordingly, in the first meeting and $25 \%$ and $29 \%$ in the second meeting) and in the case of stopping not prevented signals (33\% and $16 \%$ in the first meeting and $25 \%$ and $27 \%$ in the second meeting). The distributions of the proportions of prevented signals were not substantially skewed, $\gamma_{1}=0.3$ for the first meeting and $\gamma_{1}=-0.22$ for the second meeting. Neither were the distributions of the stopped signals, $\gamma_{1}=0.32$ and -0.33 .

Two dependent variables were taken into account as measures of performance in the task: the number of signals prevented and the number of signals stopped during their presentation. The task was performed in two series. There was a difference in the proportion of 
prevented or stopped signals in the first series between the control and the experimental group, $M_{\mathrm{C}}=.76, M_{\mathrm{E}}=.57, t(113)=3.52, p<.001, d$ $=0.65$. The difference in the proportion of prevented signals was not significant, $M_{\mathrm{C}}=.32, M_{\mathrm{E}}=.38, t(114.33)=-1.14, p=.26, d=-.21$, but the difference in the proportion of "stopping-the-not-avoided" signals was significant, $M_{\mathrm{C}}=.62, M_{\mathrm{E}}=.29, t(114.89)=4.8, p<.001, d=0.88$. Also, there was a difference in the proportion of prevented or stopped signals in the second series between the control and the experimental group, $M_{\mathrm{C}}=.95, M_{\mathrm{E}}=.82, t(87.9)=4.23, p<.001, d=0.78$. The difference in the proportion of prevented signals was not significant, $M_{\mathrm{C}}=$ $.55, M_{\mathrm{E}}=.63, t(110.56)=-1.02, p=.31, d=-.19$, but the difference in the proportion of stopping-the-not-avoided signals was significant, $M_{\mathrm{C}}$ $=.73, M_{\mathrm{E}}=.34, t(102.67)=4.98, p<.001, d=0.97$ (see Figure 4$)$.

We also tested if the level of uncertainty (in the last three tasks) was a mediator between experimental treatment and performance in the escape/avoidance learning task. The mediation analysis showed no significant mediation contribution for prevented or stopped signals $\left(\Delta R^{2}\right.$ $=-.23, p=.37)$, and neither for prevented signals $\left(\Delta R^{2}=.35, p=.67\right)$, nor for stopping-the-not-avoided signals $\left(\Delta R^{2}=-.093, p=.67\right)$.

\section{Hypothesis 2: Divergent Thinking Fluency}

The divergent thinking fluency task consisted of three questions, to each of which the participants could give any number of responses. The mean number of responses given to the first Question as $2.63(S D=$ 0.94 , range: 1,6$)$, to the second question $5.32(S D=2.14$, range: 2,16$)$, and to the third question $4.11(S D=2.6$, range: 0,12$)$. The numbers of responses given to the questions were correlated (from $r=.33$ to $r=$ $.54)$. Test reliability was acceptable, $\alpha=.65,95 \%$ CI $[.46, .84]$. The mean value of responses to all three questions was used as the measure of task performance. The mean value of the measure was $4.02(S D=1.55$, range: $1,10.67)$. The distribution of the measure was not normal $(W=$ $.92, p<.001)$ and positively skewed $\left(\gamma_{1}=1.3\right)$.

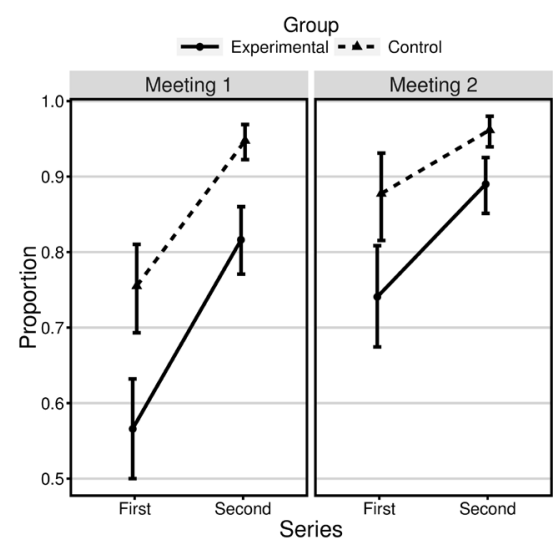

FIGURE 4.

Mean proportion of signals for which the participants responded either before they started (prevented) or over the time of their duration (stopped) in the first and second meeting shown for the control and experimental group. The bars show $95 \%$ confidence intervals for the means.
The mean number of responses given in the divergent fluency task by participants in the control group was 3.98 (2.62, 5.24, and 4.09 for Questions 1, 2, and 3, respectively). In the experimental group, the mean value was $4.06(2.64,5.41$, and 4.14 , respectively). There was neither a significant influence of group on performance in the divergent fluency task, $t(107.87)=-0.27, p=.78, d=-.051$, nor in the second meeting, $t(113.36)=-0.65, p=.52, d=-.012$.

\section{Hypothesis 3: Exhaustion Symptoms in Self-Report}

The reliability of the exhaustion symptoms questionnaire was fair, based on data collected during the first meeting ( $\alpha=.74,95 \%$ CI [.65, .83]). The lowest correlation with the total score was .27 (Item 11), with the mean correlation being .51.The reliability was fair as well, based on the data collected during the second meeting ( $\alpha=.82,95 \%$ CI [.75, .89]). The lowest correlation with the total score was .49 (Item 1), the mean correlation being .58. The distribution of exhaustion measures was normal in the data from the first meeting $\left(W=.96, p=.11, \gamma_{1}\right.$ $=0.21)$ but not in the data from the second meeting $(W=.97, p=$ $\left..004, \gamma_{1}=0.64\right)$. The measures from the first and second meeting were correlated, $r=.48,95 \%$ CI $[.32, .61]$. The item discrimination indices varied from .13 to .5 (the first meeting) and from .2 to .49 (the second meeting).

No significant difference between the control and the experimental group in the measure of exhaustion recognition was noted, neither during the first meeting, $t(103.5)=-1.25, p=.21, d=-.23$, nor even during the second one, $t(100.55)=1.65, p=.1, d=0.31$. The Bayes factor for the comparison of the null hypothesis versus the alternative is neither sufficiently high to be conclusive in the data from the first meeting $(K=$ $1.87)$ nor in the data from the second meeting $(K=1.41)$.

\section{Hypothesis 4: Escape/avoidance Learning in the Second Meeting}

The proportion of signals prevented or stopped in the escape/avoidance learning task during the second meeting was higher in the control group than in the experimental group in the first series, $M_{\mathrm{C}}=.88, M_{\mathrm{E}}$ $=.74, t(112.57)=2.53, p=.013, d=0.47$. The proportion of prevented signals did not differ between the groups, $M_{\mathrm{C}}=.46, M_{\mathrm{E}}=.57, t(114.72)$ $=-1.57, p=.12, d=-.29$, but the proportion of stopping-the-notavoided signals did differ, $M_{\mathrm{C}}=.78, M_{\mathrm{E}}=.41, t(92.81)=4.49, p<.001$, $d=0.91$. The proportion was also different between the groups in the second series, $M_{\mathrm{C}}=.96, M_{\mathrm{E}}=.89, t(89.43)=2.75, p=.007, d=0.51$. The proportion of prevented signals did not differ between the groups in the second series, $M_{\mathrm{C}}=.52, M_{\mathrm{E}}=.63, t(114.72)=-1.49, p=.14, d=$ -.28 , but the proportion of stopping-the-not-avoided signals did differ, $M_{\mathrm{C}}=.73, M_{\mathrm{E}}=.34, t(102.67)=4.48, p<.001, d=0.97$ (see Figure 4$)$.

We also checked if the difference between groups varied between the first and second meeting. The repeated-measures ANOVA showed that there was no difference between meetings in the first series (prevented or stopped signals, $p=.37$; prevented signals, $p=.5$, stoppingthe-not-avoided signals, $p=.9$ ). In the second series, there was neither a difference for prevented signals $(p=.47)$ nor for stopping-the-not- 
avoided signals $(p=.7)$, but there was a difference for prevented or stopped signals: In the second meeting the difference between groups was smaller than in the first meeting, $F(1,115)=6.71, p=.012, \eta^{2}=$ .0092 .

\section{DISCUSSION}

The results of the study indicate that exposure to the unsolvable task may negatively influence performance in subsequent cognitive tasks in persons with mild intellectual disability. The situation in the experiment may be compared to a situation at school when a person with intellectual disability is presented with a problem that is overly demanding. In our study, such an exposure affected only the performance in the task which required hypothesis-testing activity.

As predicted in our first hypothesis, persons in the experimental group performed significantly worse than the controls in the escape/ avoidance learning task, having difficulties finding the correct way to escape the signal during its exposure. In the Sędek and Kofta (1990) study, students from the general population displayed difficulties in the complex avoidance condition and not in the cognitively less demanding escape condition. According to the cognitive exhaustion theory (Kofta \& Sędek, 1999; Sędek \& Kofta, 1990; Von Hecker et al., 2013, 2000), this result can be explained by the fact that the limited access to cognitive resources manifests itself especially in the performance of tasks which require more cognitive effort, while in the simple tasks, the available resources still allow a person to perform at a standard level. Our results suggest that persons with intellectual disability present a similar performance in the avoidance condition, but significantly differ in escaping the signal, as if the unsolvable task exposure resulted rather in increased passivity and not in the problems with finding the correct answer to stop the signal while engaged in such activity. This may be due to the fact that diminution in already limited cognitive resources in persons with intellectual disability leads to a tendency to hold back resources in mental operations, which undermines performance even in simple tasks. Those persons who were able to engage in the hypothesistesting activity by trying to find the solution were able to avoid the signal as well as the control group.

The second hypothesis, in which we predicted that the cognitive exhaustion state would negatively influence the performance in the divergent thinking fluency task, was not confirmed. Those in the experimental group did not significantly differ from the controls in the number of ideas generated. The result suggested that persons with intellectual disability may display fewer difficulties in tasks which, at the beginning, do not set the standard for the approved performance than in tasks which require them to achieve a specific goal, such as the escape/avoidance learning task. In accordance with the results of studies on learned helplessness in persons with intellectual disability (Weisz, 1999), we may explain our results by relating them to the probable history of failure in the second type of tasks and not in the first one. The second explanation is that the result may be also related to the sequence of the tasks in the experiment. The divergent thinking fluency task was given immediately after the solvable escape/avoidance learning task, which might have allowed persons to regain control over their cognitive resources. The positive effects of regaining control have also been considered by other authors (Bukowski et al., 2014).

The third hypothesis stated that persons with intellectual disability would not identify the symptoms of the cognitive exhaustion state. In the answers given in the questionnaire, there was no significant difference between the groups during the first and the second meeting. However, the results of Bayesian analysis are not conclusive as far as this hypothesis is concerned. The probable lack of ability to recognize the symptoms of cognitive exhaustion may be explained by the more general deficit in the ability to recognize the level of one's performance (Dunning et al., 2003; Ehrlinger \& Dunning, 2003; Ehrlinger et al., 2008) or by the difficulties in connecting the performance to internal causes observed in persons with intellectual disability (Wehmeyer, 1994, 2001). In our study, the internal cause of performance deficits was related to the temporarily decreased cognitive resources.

The fourth hypothesis, which predicted that exposure to the unsolvable tasks would have a long-term effect on learning effectiveness, was supported. After a week, the experimental group, despite being given success feedback in the discrimination task, still had more difficulties in escaping the signals. This may be due to the fact that the control group could benefit from the previous experience, whereas the diminished learning ability in the experimental group during the previous meeting resulted in retaining the difference in performance.

There are several limitations to the study, which need to be considered in future application. First, we decided to inform persons in the experimental group that the feature or element chosen in the discrimination task is incorrect since persons with intellectual disability may be less critical in the evaluation of their performance. We did no $t$-test whether the inconsistent information flow would negatively influence performance without such feedback. Another limitation is that the length of exposure to the unsolvable problem could be significant to the effects observed in the subsequent tasks. It is possible that longer exposure would decrease the performance in both tasks and not only in the escape/avoidance learning task. Also, it is important to underline that the relation of the cognitive exhaustion state and divergent thinking fluency was not tested in persons without intellectual disability, so we cannot rule out the possibility that the effects are specific to the tested group. Finally, the lack of difference in the self-report may not be due to the inability to recognize symptoms of learned helplessness but to other factors, such as an unwillingness to display discontent before the experimenter.

\section{CONCLUSIONS}

In the described study, we used for the first time the informational model of learned helplessness to test persons with intellectual disability. The results of the study give further credence to the well-described negative effect of learned helplessness on escape/avoidance learning (Peterson et al., 1993; Weisz, 1999). However, we did not observe that persons with intellectual disability had the ability to recognize the symptoms of diminished learning, which suggests that such persons 
may not be aware of cognitive limitations in the same way that persons from the general population are (Sędek \& Kofta, 1990). If these results are confirmed in future research, they should have implications on educational practices for persons with intellectual disability related to failure situations in the classroom and the self-reported recognition of cognitive limitations.

\section{AUTHOR NOTE}

The research was supported by a grant of the Polish Ministry of Science and Higher Education no.0486/H03/2010/39.

\section{REFERENCES}

American Psychiatric Association (2013). American Psychiatric Association: Diagnostic and statistical manual of mental disorders (5th ed.) Washington, DC: Author. doi: 10.1176/appi. books.9780890425596

Basil, C. (1992). Social interaction and learned helplessness in severely disabled children. Augmentative and Alternative Communication, 8, 188-199. doi: 10.1080/07434619212331276183

Benderek, M., Muhlmann, C., Jauk, E., \& Neubauer, A. C. (2013). Assessment of divergent thinking by means of the subjective top-scoring method: Effects of the number of top-ideas and time-on-task on reliability and validity. Psychology of Aesthetics, Creativity, and the Arts, 7, 341-349. doi: 10.1037/a0033644 WWW Benjamini, Y., \& Yekutieli, D. (2001). The control of the false discovery rate in multiple testing under dependency. The Annals of Statistics, 29, 1165-1188. doi: 10.1214/aos/1013699998

Bukowski, M., Asanowicz, D., Marzecova, A., \& Lupianez, J. (2014). Limits of control: The effects of uncontrollability experiences on the efficiency of attentional control. Acta Psychologica, 154, 43-53. doi: 10.1016/j.actpsy.2014.11.005 WWW

Dunning, D., Johnson, K., Ehrlinger, J., \& Kruger, J. (2003). Why people fail to recognize their own competence. Current Directions in Psychological Science, 12, 83-87. doi: 10.1111/14678721.01235

Ehrlinger, J., \& Dunning, D. (2003). How chronic self-views influence (and potentially mislead) estimates of performance. Journal of Personality and Social Psychology, 84, 5-17. doi: 10.1037/0022-3514.84.1.5 $\overline{\mathrm{WWW}}$

Ehrlinger, J., Johnson, K., Banner, M., Dunning, D., \& Kruger, J. (2008). Why the unskilled are unaware: Further explorations of (absent) self-insight among the incompetent. Organizational Behavior and Human Decision Processes, 105, 98-121. doi: 10.1016/j.obhdp.2007.05.002 |wWw

Gargiulo, R. M., \& O'Sullivan, P. S. (1986). Mildly mentally retarded and nonretarded children's learned helplessness. American Journal of Mental Deficiency, 91, 203-206. WWW

Gargiulo, R. M., O'Sullivan, P. S., \& Barr, N. J. (1987). Learned helplessness in reflective and impulsive mentally retarded and nonretarded children. Bulletin of the Psychonomic Society, 25, 269-272. doi: 10.3758/BF03330352
Goharpey, N., Crewther, D. P., \& Crewther, S. G. (2009). Intellectual disability: Beyond IQ scores. In L. C. Eklund, \& A. S. Nyman (Eds.), Learning and memory developments and intellectual disabilities (pp. 157-174). New York, NY: Nova Science Publishers Inc.

Greenspan, S. (1999). What is meant by mental retardation? International Review of Psychiatry, 11, 6-18. doi: 10.1080/09540269974474

Harris, J. C. (2006). Intellectual disability. Understanding its development, causes, classification, evaluation, and treatment. Oxford, England: Oxford University Press.

Hatfield, J., \& Job, R.F. S. (1998). Random yoking: An alternative to feedback procedures for preventing superstition in the human "learned helplessness" paradigm. Learning and Motivation, 29, 416-434. doi: 10.1006/Imot.1998.1010

Heward, W. L. (2006). Exceptional children. An introduction to special education (8th ed). London, England: Pearson Education Inc.

Hodapp, R. M. (2001). Etiology and personality motivation: Direct and indirect effects. In H. N. Switzky (Ed.), Personality and motivational differences in persons with mental retardation ( $p p$. 257-282). New York, NY: Taylor \& Francis Group.

Hodapp, R. M., Burack, J. A., \& Zigler, E. (1998). Developmental approaches to mental retardation. In J. A. Burack, R. M. Hodapp, \& E. Zigler (Eds.), Handbook of mental retardation and development (pp. 3 - 19). Cambridge, MA: University Press.

larocci, G., \& Petrill, S. A. (2012). Behavioral genetics, genomics, intelligence, and mental retardation. In J. A. Burack, R. M. Hodapp, G. Iarocci, \& E. Zigler (Eds.), The Oxford handbook of intellectual disability and development (pp. 13-29). Oxford, England: University Press.

Kofta, M., \& Sędek, G. (1999). Uncontrollability as irreducible uncertainty. European Journal of Social Psychology, 29, 577-590. doi: $\quad$ 10.1002/(SICI)1099-0992(199908/09)29:5/6<577::AIDEJSP947>3.0.CO;2-K

LoLordo, V. M., \& Taylor, T. L. (2001). Effects of uncontrollable aversive events: Some unsolved puzzles. In R. R. Mowrer \& S. B. Klein (Eds.), Handbook of contemporary learning theories (pp. 469-504). Mahwah, NJ: Lawrence Erlbaum Associates Inc.

Maier, S. F., \& Seligman, M. E. P. (1976). Learned helplessness: Theory and evidence. Journal of Experimental Psychology: General, 105, 1, 3-46. doi: 10.1037/0096-3445.105.1.3

Matute, H. (1994). Learned helplessness and superstitious behavior as opposite effects of uncontrollable reinforcement in humans. Learning and Motivation, 25, 216-232. doi: 10.1006/ Imot.1994.1012

Mikulincer, M., Kedem, P., \& Zilkha-Segal, H. (1989). Learned helplessness, reactance, and cue utilization. Journal of Research in Personality, 23, 235-247. doi: 10.1016/0092-6566(89)90026-3

Minor, T. R., Jackson, R. L., \& Maier, S. F. (1984). Effects of task-irrelevant clues and reinforcement delay on choice-escape learning following inescapable shock: Evidence for a deficit in selective attention. Journal of Experimental Psychology: Animal Behavior Processes, 10, 543-556. doi: 10.1037/0097-7403.10.4.543 WWW 
Morey, R. D., \& Rouder, J. N. (2014). BayesFactor: Computation of Bayes factors for common designs. $\mathrm{R}$ package version 0.9.7. [Computer software manual]. Retrieved from http://CRAN.Rproject.org/package=BayesFactor

Overmier, J. B. (2002). On learned helplessness. Integrative Physiological \& Behavioral Science, 37, 4-8. doi: 10.1007/ BF02688801 WWW

Overmier, J. B., \& Seligman, M. E. P. (1967). Effects of inescapable shock upon subsequent escape and avoidance responding. Journal of Comparative and Physiological Psychology, 63, 28-33. doi: $10.1037 / \mathrm{h} 0024166$ WWW

Peterson, C., Maier, S. F., \& Seligman, M. E. P. (1993). Learned helplessness. A theory for the age of personal control. Oxford, England: University Press.

Pittman, T. S., \& D'Agostino, P. R. (1989). Motivation and cognition: Control deprivation and the nature of subsequent information processing. Journal of Experimental Social Psychology, 25, 465480. doi: 10.1016/0022-1031(89)90001-2

Pittman, T. S., \& Pittman, N. L. (1980). Deprivation of control and the attribution process. Journal of Personality and Social Psychology, 39, 377-389. doi: 10.1037/0022-3514.39.3.377

Reed, P., \& Antonova, M. (2007). Interference with judgments of control and attentional shift as a result of prior exposure to controllable and uncontrollable feedback. Learning and Motivation, 38, 229-241. doi: 10.1016/j.Imot.2006.08.005

Reynolds, W. M., \& Miller, K. L. (1985). Depression and learned helplessness in mentally retarded and nonmentally retarded adolescents: An initial investigation. Applied Research in Mental Retardation, 6, 295-306. doi: 10.1016/0270-3092(85)90003-7 WWW

Richards, S. B., Brady, M. P., \& Taylor, R. L. (2015). Cognitive and intellectual disabilities. Historical perspectives, current practices, and future directions. New York, NY: Taylor \& Francis.

Schalock, R. L., Luckasson, R. A., Shogren, K. A., BorthwickDuffy, S., Bradley, V., Buntinx, W. H., . . Yeager, M. H. (2007). The renaming of mental retardation: Understanding the change to the term intellectual disability. Intellectual and Developmental Disabilities, 45, 116-124. doi: 10.1352/19349556(2007)45[116:TROMRU]2.0.CO;2 WW

Sędek, G., \& Kofta, M. (1990). When cognitive exertion does not yield cognitive gain: Toward an informational explanation of learned helplessness. Journal of Personality and Social Psychology, 58, 729-743. doi: 10.1037/0022-3514.58.4.729 WWW

Sędek, G., Kofta, M., \& Tyszka, T. (1993). Effects of uncontrollability on subsequent decision making: Testing the cognitive exhaustion hypothesis. Journal of Personality and Social Psychology, 65, 1270-1281. doi: 10.1037/0022-3514.65.6.1270 WWW

Seligman, M. E. P., \& Maier, S. F. (1967). Failure to escape traumatic shock. Journal of Experimental Psychology, 74, 1-9. doi: 10.1037/ h0024514
Snyder, T. D., \& Dillow, S. A. (2015). Digest of education statistics 2013 (NCES 2015-011). Washington, DC: National Center for Education Statistics, Institute of Education Sciences, U.S. Department of Education. Retrieved from https://nces.ed.gov/ pubs2015/2015011.pdf

United Nations Educational, Scientific and Cultural Organization (2009). Policy guidelines on inclusion in education. Paris, France: United Nations Educational, Scientific and Cultural Organization. Retrieved from http://unesdoc.unesco.org/ images/0017/001778/177849e.pdf

Utley, C. A., Hoehn, T. P., Soraci, S. A., Jr., \& Baumeister, A. A. (1993). Motivational orientation and span of apprehension in children with mental retardation. The Journal of Genetic Psychology, 154, 289-295. doi: 10.1080/00221325.1993.10532182

Von Hecker, U., \& Sędek, G. (1999). Uncontrollability, depression, and the construction of mental models. Journal of Personality and Social Psychology, 77, 833-850. doi: 10.1037/0022-3514

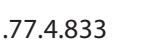

Von Hecker, U., Sędek, G., \& Brzezicka, A. (2013). Impairments in mental model construction and benefits of defocused attention: Distinctive facets of subclinical depression. European Psychologist, 18, 35-46. doi: 10.1027/1016-9040/a000133

Von Hecker, U., Sędek, G., \& McIntosh, D. N. (2000). Impaired systematic, higher order strategies in depression and helplessness: Testing implications of the cognitive exhaustion model. In U. Von Hecker, S. Dutke, \& G. Sędek (Eds.), Generative mental processess and cognitive resources. Integrative research on adaptation and control (pp. 245-275). Dordrecht, The Netherlands: Kluwer Academic Publishers.

Wehmeyer, M. L. (1994). Perceptions of self-determination and psychological empowerment of adolescents with mental retardation. Education and Training in Mental Retardation and Developmental Disabilities, 29, 9-21.

Wehmeyer, M. L. (2001). Self-determination and mental retardation. International Review of Research in Mental Retardation, 24, 1-48. doi: 10.1016/S0074-7750(01)80004-5

Weisz, J. (1979). Perceived control and learned helplessness among mentally retarded and nonretarded children: A developmental analysis. Developmental Psychology, 15, 311-319. doi: 10.1037/0012-1649.15.3.311

Weisz, J. (1981). Learned helplessness in black and white children identified by their schools as retarded and nonretarded: Performance deterioration in response to failure. Developmental Psychology, 17, 499-508. doi: 10.1037/00121649.17.4.499

Weisz, J. (1999). Cognitive performance and learned helplessness in mentally retarded persons. In E. Zigler \& D. Bennet-Gates (Eds.), Personality development in individuals with mental retardation (pp. 17-46). Cambridge, MA: University Press.

RECEIVED 16.06.2016 | ACCEPTED 02.11.2016 